\title{
Criatividade e processo de projeto escolar: jogo de tabuleiro como ferramenta de apoio
}

\author{
Creativityandtheschool design process: theboard game as \\ a supporting tool
}

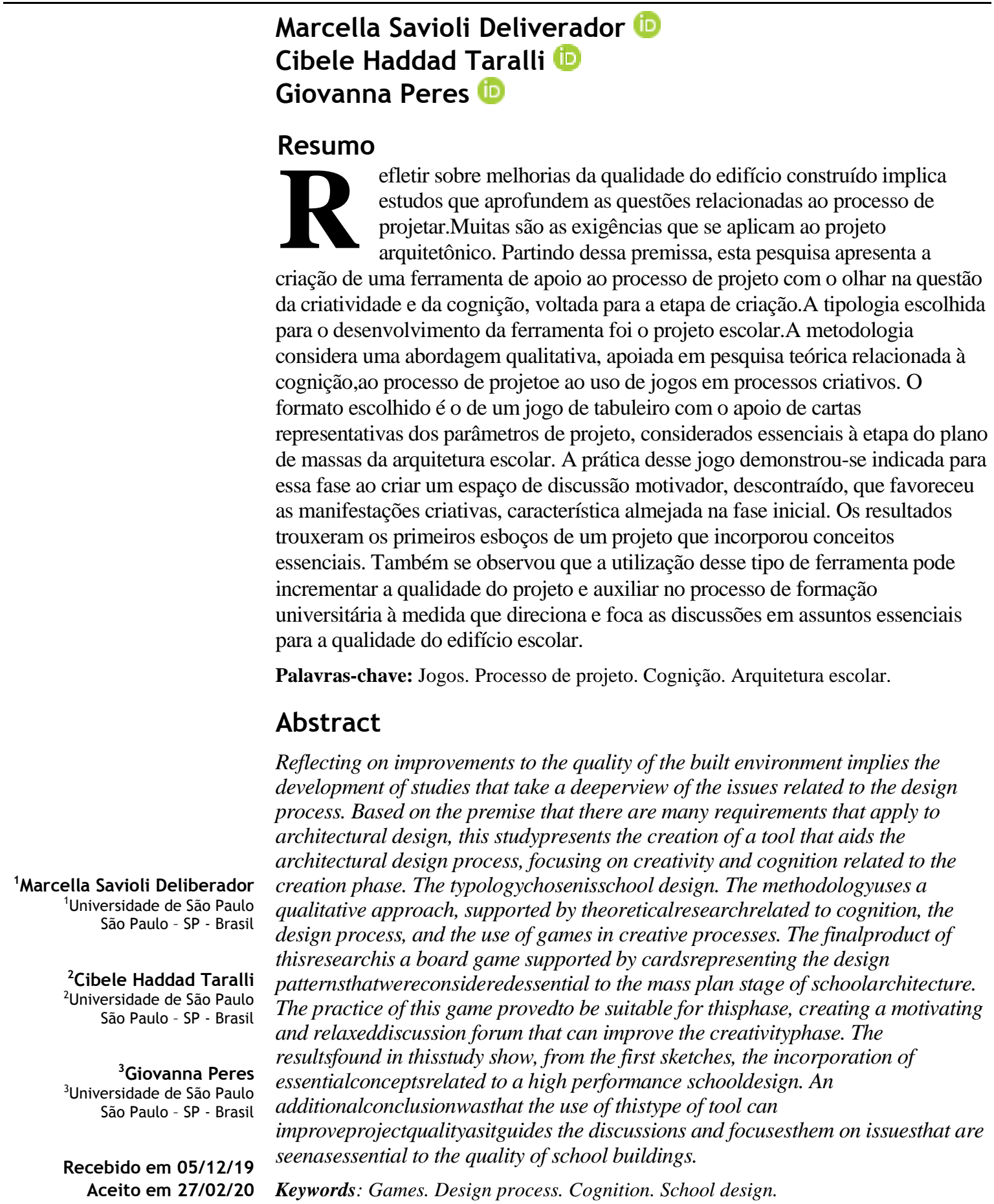




\section{Introdução}

Refletir sobre melhorias da qualidade do edifício construído implica necessariamente aprofundar as questões relacionadas ao processo de projetar em arquitetura. Os avanços tecnológicos e as mudanças sociais e econômicas, vividas ao longo das últimas décadas, alteraram diversos processos de trabalho, não sendo diferente na área da arquitetura. Na prática de pesquisa, muitos dos novos temas trouxeram uma abordagem mais crítica e especulativa à pesquisa em projeto, enquadrando as novas questões de uma maneira diferente das mais tradicionais, focadas em abordagens baseadas em evidências (LLYOD, 2017).

Muitas são as exigências que se aplicam ao projeto arquitetônico, desde as inerentes à atividade ou uso da edificação até os aspectos contextuais relacionados à sociedade (KOWALTOWSKI et al., 2006). Assim, coloca-se a importância de se refletir sobre novos métodos de apoio ao processo criativo.

Quando se discute o desempenho das equipes de projeto, pesquisadores sempre apontam para a necessidade da compreensão da cognição, especialmente durante o processo criativo. Os estudos na área da neurologia continuam avançando sobre as questões cognitivas do cérebro, buscando compreender como ocorre o processamento das informações por meio da percepção e das interações com o ambiente físico, e do raciocínio. Os saberes, habilidades e experiências também fazem parte desse processo (FLORIO, 2011). Nessa perspectiva, a pesquisa interdisciplinar combina sinais dos estudos em projeto com a neurociência cognitiva, o que pode ser um instrumento para testar diversas hipóteses de pesquisa para os estudos na área de projeto (ALEXIOU et al., 2009).

Nesse contexto, o aprofundamento do conhecimento sobre as diversas e novas formas de apoio ao processo de projeto em arquitetura, dando atenção às questões da cognição, da criatividade, da colaboração, da organização da informação e da produtividade e gestão das etapas, é essencial, pois vislumbra a melhoria da qualidade do produto final. Sabe-se que o processo de projeto não é uma atividade linear (FLORIO, 2011; LAWSON, 2011) e que o processo criativo arquitetônico é uma atividade complexa que envolve múltiplas habilidades cognitivas e motoras. Cabe ao projetista ser capaz de traduzir, nos aspectos formal e funcional, as necessidades impostas pelos agentes envolvidos no projeto (FERNANDES, 2017).

As equipes de planejamento e projeto necessitam tomar decisões, o que significa que as discussões devem chegar a um consenso. Essas experiências colaborativas, que incluem diversas pessoas, usuários, especialistas, etc., com os mais variados conhecimentos e interesses, demandam que se encontrem métodos que facilitem a dinâmica do processo colaborativo (SANDERS; BRANDT; BINDER, 2010).

Nas pesquisas recentes, os apoios no formato de jogos atingiram os mais diversos grupos, incluindo não somente os projetistas e usuários, mas todos os agentes envolvidos (BRANDT; MESSETER; BINDER, 2008; BAPTISTA et al., 2016; FERNANDES, 2017). Experiências com aprendizado e com processo colaborativo entre as equipes e profissionais envolvidos na projetação por meio de jogos indicam que essa é uma ferramenta de grande interesse para todas as áreas de estudo das ciências (CLARK; QIAN, 2016).

As características dos jogos se revelam como um grande potencial para a resolução de problemas concretos, e é disso que se vale a teoria da gameficação, que define esse conceito como o processo de utilização de pensamento de jogos e dinâmicas para engajar audiências e resolver problemas (ALVES, 2014).

Esta pesquisa discute a criatividade ligada ao projeto arquitetônico, induzida a partir de jogos de apoio, que podem beneficiar o processo de projeto. $\mathrm{O}$ estudo do funcionamento do cérebro no processo criativo pode fundamentar a aplicação desses jogos, indicando em quais etapas cognitivas elas podem oferecer contribuição mais significativa, em uma reflexão aprofundada que relaciona projeto, criação, cognição e ferramentas de apoio (Figura 1). Observa-se que, desde o início do processo, cognição e ideação caminham juntas, interagindo ao longo de toda a etapa criativa.

Figura 1 - Processo de projeto e cognição

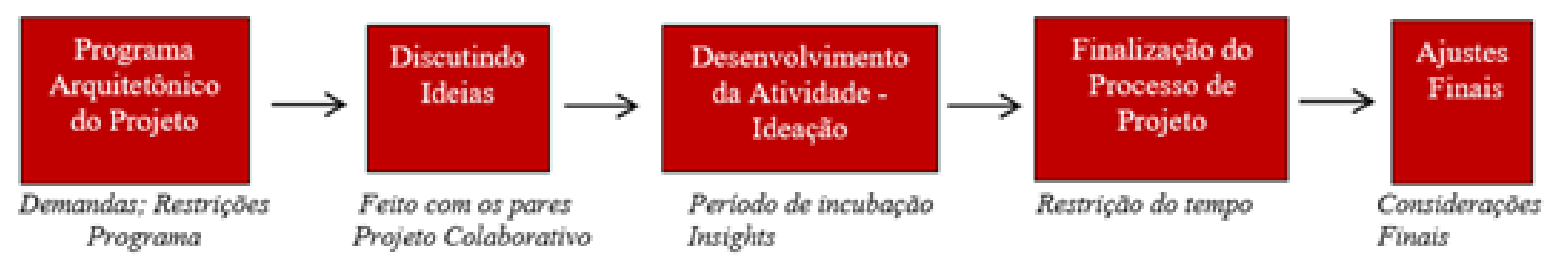

Fonte: adaptado de Lloyd, Lawson e Scott (1995). 
O processo cognitivo voltado às questões de criatividade está relacionado às diversas etapas do processo de projeto e à aquisição do conhecimento, na busca das melhores soluções para o problema estabelecido em cada uma das etapas. Tais etapas incluem a formulação do problema, a geração da solução propriamente dita e o gerenciamento do processo como um todo (CROSS, 2001). Desse modo, cabe explorar diversas e novas formas de apoio a essas etapas do processo de projeto em arquitetura.

Apresenta-se neste artigo a criação de uma ferramenta de apoio que ofereça colaboração ao processo com o olhar na questão da criatividade e da cognição e testá-la na fase de criação do projeto arquitetônico. A tipologia escolhida para a ferramenta em questão foi o projeto escolar. Essa escolha se justifica dada a importância social das escolas e o caráter complexo que seu projeto recebe, principalmente em função da ampla variedade de usuários desse tipo de edifício e da dinâmica dos aspectos pedagógicos, em constante mudança e evolução. Assim, o jogo aqui proposto pretende subsidiar o desenvolvimento das primeiras ideias do projeto escolar, na fase denominada plano de massas.

\section{Fundamentação teórica: criatividade, processo de projeto e o ambiente escolar}

A concepção de uma nova ferramenta de apoio ao processo de projeto escolar voltada para a etapa inicial de criação demandou estabelecer como referencial teórico três eixos:

(a) o plano de massas no processo de projeto em arquitetura;

(b) os conceitos da arquitetura escolar; e

(c) os jogos como dinâmicas de apoio ao processo de projeto.

O primeiro eixo foi estudado com enfoque na obtenção de uma definição do conceito de plano de massas, nome usualmente atribuído à primeira elaboração e/ou à representação, ainda que esquemática, da ideia de um projeto arquitetônico. O segundo pretendeu levantar os conceitos a que os profissionais deveriam atender para o projeto de uma escola de alto padrão de desempenho segundo a literatura sobre o tema. O terceiro buscou dar um embasamento teórico ao desenvolvimento do jogo piloto, de forma a contribuir com o incremento da qualidade do processo de projeto dos profissionais.

\section{Plano de massas no processo de projeto em arquitetura}

A compreensão do processo do projeto implica, inicialmente, entender que ele pode ocorrer de diversas formas e por meio de inúmeras possibilidades metodológicas, dependendo de como cada arquiteto organiza suas ideias e as transforma em projetos concretos (KOWALTOWSKI et al., 2011).

A criatividade é o elemento-chave e permeia a atividade de projetar em todas as suas etapas. Apesar disso, pesquisas sobre o processo criativo ainda não foram completamente mapeadas e esgotadas, o que justifica a importância de novos estudos para a aplicação de métodos de estímulo à criatividade diretamente no processo de projeto arquitetônico. Essa constatação se apoia na percepção de que há dificuldade em se fazer uma generalização do processo criativo, já que são muitos os aspectos subjetivos, individuais e intuitivos nele presentes (BIANCHI, 2008).

De forma simplificada, na maioria dos estudos e pesquisas, o processo de projeto compreende três atividades intelectuais básicas:

(a) análise (etapa de programação na qual são coletadas informações que identifiquem os problemas a serem solucionados e os parâmetros projetuais);

(b) síntese (etapa de geração de ideias para solucionar espacialmente os problemas levantados); e

(c) avaliação (etapa na qual as soluções trazidas serão testadas e avaliadas) (KOWALTOWSKI et al., 2011).

As etapas iniciais são essenciais ao processo criativo, pois é nesse momento que surgem, de forma potencializada, as melhores soluções para cada uma das problemáticas enfrentadas, e tal fato pode justificar a importância do projeto colaborativo. Essa fase inicial compreende a leitura da problemática, mediante a análise dos fatos coletados no programa arquitetônico e as primeiras propostas de síntese, que associam a criatividade com as tomadas de decisão, responsáveis pelas primeiras soluções de organização funcional, formal, tecnológica. Assim, o arquiteto processará e ordenará as informações recebidas para formar conceitos, princípios e referências (KOWALTOWSKI et al., 2011). 
Lawson (2011) destaca que esse momento de transição entre a etapa de análise e a etapa de síntese confere um grande desafio ao projetista: as informações que, reunidas na etapa de análise, contribuirão para que de fato se possa chegar a uma proposta inicial de edifício. Esse é o momento do processo conhecido como plano de massas, que constitui e configura as primeiras soluções espaciais propostas e as representa de forma gráfica, traduzindo as informações coletadas na análise em conceitos fundamentais, os quais subsidiam o desenvolvimento do projeto arquitetônico.

O plano de massas traz consigo questões que lhe são próprias, pois se trata do primeiro modelo de expressão bidimensional ou volumétrica, um resultado gráfico preliminar daquilo que se concluiu das pesquisas e levantamentos. Para facilitar esse processo, nessa fase de plano de massas, a literatura sugere o uso de maquetes ou modelos físicos além dos desenhos, esquemas ou croquis analógicos ou digitais. Tais artefatos funcionam tanto como canais de comunicação que expressam o resultado da etapa analítica do que se imagina como futuro edifício, quanto como via de comunicação entre o arquiteto e o futuro cliente ou usuário (KOWALTOWSKI et al., 2011; MARANGONI, 2011).

O desenvolvimento de um plano de massas necessita de uma etapa anterior de programação completa, que levantará todos os fatos relacionados ao projeto. Para essa etapa, é essencial que sejam identificados os conceitos que explicitem o problema a ser resolvido pelo projetista, ou seja, é necessário possuir conceitos definidores da linha de pensamento inicial do arquiteto, para que se possam esboçar as primeiras ideias. É importante colocar que entre o conceito e o plano de massas o que se estabelece não é uma relação de referência, mas, sim, de diálogo (LEITE, 2000).

O plano de massas, além de ser uma forma de verificação de uma ideia, é a tradução formal e visual de conceitos elaborados mentalmente, ou seja, aquilo que foi levantado da etapa analítica e deve ser expresso formalmente com um esboço inicial do futuro edifício. Ele confere, assim, uma base para discussão de propostas que permite a participação de outras pessoas indispensáveis ao processo (no caso das escolas, os usuários são pais, alunos, funcionários, professores, etc.), e não somente os profissionais da área de arquitetura (KOWALTOWSKI, 2011).

O conhecimento dos conceitos essenciais para oferecer uma experiência espacial adequada aos usuários do ambiente escolar atual é tarefa dos profissionais envolvidos com essa arquitetura. E o momento no qual o arquiteto organiza esses conceitos de forma a elaborar o plano de massas é objeto de estudo da presente pesquisa. Considera-se que o processo criativo associado à etapa de desenvolvimento do plano de massas envolve uma série de processos mentais ligados à cognição, que pode ser subsidiado pelo uso de ferramentas que ajudem na tomada de decisão e na organização dos conceitos-chave de desenvolvimento do projeto.

\section{Conceitos da arquitetura escolar}

A literatura sobre arquitetura escolar é bastante ampla e difundida, discutindo conceitos e partidos que as escolas devem apresentar em função das pedagogias atuais (SANOFF, 1994; DUDEK, 2007; AZEVEDO; BASTOS; BLOWER, 2007; NAIR; FIELDING; LACKNEY, 2013; HILLE, 2011; DESIGN; FURNITURE; DESIGN, 2010; WOOLNER, 2010; BARRETT et al., 2013, 2015; UCCI et al., 2015; OBLINGER, 2006; BOYS, 2011; PLOTKA, 2016; SOUZA, 2018). A literatura demonstra a importância em relacionar a arquitetura com a pedagogia desde os primeiros esboços. Também indica a complexidade trazida para a tipologia escolar mediante duas questões principais:

(a) a dinâmica dessas pedagogias e a consequente necessidade de adaptação do espaço arquitetônico; e

(b) a variedade dos tipos de usuários (alunos, professores, funcionários, pais e comunidade) com desejos e necessidades bastante distintos.

Sanoff (2001), por exemplo, ao defender a influência que os espaços escolares possuem sobre o processo de aprendizagem,trata de princípios que devem ser adotados no projeto de todas as escolas, como ambientes estimulantes, presença de lugares para o ensino em grupo, conexão entre os espaços do interior com o exterior, áreas públicas incorporadas ao espaço escolar, segurança, variedade espacial, interação com o ambiente externo, flexibilidade, riqueza de recursos e ambientes ativos e passivos.

Hertzberger (1986) também reflete sobre as características as quais o arquiteto deve se atentar ao projetar uma escola para que o espaço permita que o aprendizado seja atrativo. Segundo ele, o projeto de escola deve priorizar a fluidez de circulação em relação às funções de programa e deve possuir uma "rua educativa", espaço de confluência entre as salas e outros espaços educativos, como biblioteca, sala de informática, refeitório, etc. 
A literatura traz ainda autores que estabeleceram parâmetros de projeto para que a experiência de aprendizado seja enriquecida em seu ambiente de ensino. Espera-se que os espaços sejam flexíveis e adaptáveis para diferentes tipos de modalidades de ensino, como ensino por tutoria, ensino por pesquisas e de projetos, ensino pelo contato com a natureza ou brincadeiras (SOUZA, 2018). Um ambiente que possui uma arquitetura estimulante permite que os alunos e outros usuários tenham diferentes tipos de experiências que colaborem com o aprendizado (PLOTKA, 2016). Segundo Design, Furniture e Design (2010), um bom projeto de ambiente de ensino é fundamental para que a experiência do aprendizado seja completa e o prédio da escola funcione como terceiro professor.

Observa-se que muitos são os conceitos indicados pela literatura como importantes para a arquitetura escolar. Muitas dessas referências organizam esses conceitos no formato de parâmetros de projeto, ou seja, utilizam a base teórica de Alexander, Ishikawa e Silverstein(2013) para o desenvolvimento de uma linguagem gráfica para a discussão de parâmetros escolares responsáveis pelas escolas consideradas de alto padrão de desempenho. Para facilitar a organização dos conceitos, as principais referências foram selecionadas e os parâmetros por elas apresentados organizados nos Quadros 1 a 3 (cada quadro apresenta os parâmetros de uma das referências selecionadas).

Desenvolver bons projeto de arquitetura que levem em consideração todos esses princípios que estão sendo discutidos significa valorizar o usuário e a comunidade. Isso implica um processo projetual que esteja comprometido com a qualidade arquitetônica final do edifício. Para o projetista, é importante compreender como são as práticas que se desenvolvem dentro dos espaços de aprendizagem para que se possa facilitar a realização do projeto educacional.

É significativo destacar que há peculiaridades de um projeto escolar em relação a outras tipologias arquitetônicas, exigindo-se do projetista atenção a isso. Pode-se dar atenção às experiências espaciais porque elas refletem no processo de aprendizado dos estudantes, na adequação dos espaços às metodologias de ensino, na incorporação de um caráter expressivo (que pode ser obtido pela forma, material e integração social e urbana), que criam significados às pessoas e à vizinhança, e o atendimento às questões e especificações projetuais de conforto ambiental (térmico, acústico e visual), que configurem características físicasfavoráveis para o desenvolvimento das funções da aprendizagem.

Assim, é dever do projetista ter acesso a esses conceitos e parâmetros essenciais para o projeto de uma escola com alto nível de desempenho.Considerando a complexidade da produção desse tipo de edifício, há a dificuldade de criar uma base comum de discussão de projeto de arquitetura escolar de alto desempenho, o que aponta para o desenvolvimento, segundoDeliberador (2016), de ferramentas de projeto como um facilitador tanto para as tomadas de decisão quanto para o estímulo à criatividade para a solução dos problemas colocados.

\section{Jogos como dinâmicas de apoio ao processo de projeto}

O processo de projeto arquitetônico traz dois princípios importantes, que o tornam ainda mais complexo:

(a) com a tecnologia tornando-se parte importante do trabalho, o projeto não é mais apenas uma questão de arquitetura e, assim, esse processo necessita de pessoas com diversas competências, o que significa cooperação e negociação de muitos personagens, com diferentes conhecimentos e com a necessária divisão de tarefas e responsabilidades; e

(b) o objeto muda constantemente, o que exige compreensão das transformações das organizações físicas (HABRAKEN; GROSS, 1987; JOHANSSON et al., 2002).

Além disso, outras questões atuais foram incluídas nos novos processos: o projeto e a tomada de decisões são um desafio crescente, com o aumento da complexidade dos conceitos de projeto e com o aumento da pressão por se preservarem energia e os demais recursos ambientais (SARHAN; RUTHERFORD, 2009). Isso significa queos profissionais envolvidos necessitam cada vez mais de ferramentas capazes de apoiar o processo de projeto em suas mais diversas etapas. Essas ferramentas podem facilitar o trabalho dos arquitetos, estimulando a participação e a interação entre eles e com outros profissionais envolvidos, além de permitirem a inclusão de futuros usuários, por meio de processos participativos (BRANDT, 2006).

Desde os anos 1990, um número crescente de estudos vem sugerindo os jogos para colaborar nas relações entre usuários e projetistas. Essas experiências colaborativas que incluem diversas pessoas, ou seja, os usuários, os agentes, a equipe de projeto, os especialistas, etc., com as mais variadas experiências, responsabilidades e interesses demandam que se encontrem ferramentasadequadas para engajar e envolver as pessoas no processo colaborativo (SANDERS; BRADT; BINDER, 2010). 
Quadro 1 - Parâmetros de projeto da arquitetura escolar segundo Building Futures

\begin{tabular}{|l|l|}
\hline \multicolumn{1}{|c|}{ Parâmetro } & \multicolumn{1}{c|}{ Descrição } \\
\hline Espaços inspiradores & $\begin{array}{l}\text { Para aqueles que estudam, trabalham e visitam, os espaços devem fornecer } \\
\text { uma experiência que indique os princípios e objetivos daquela escola. O } \\
\text { ambiente de aprendizagem deve ser um meio de ampliar o aprendizado. }\end{array}$ \\
\hline Espaços flexíveis & $\begin{array}{l}\text { Os espaços individuais e as configurações do edifício devem ser adaptáveis } \\
\text { para usos diversos no curto prazo, assim como no longo prazo. Eles devem } \\
\text { suportar a variação dos usos, da quantidade de usuários e de leiaute. }\end{array}$ \\
\hline $\begin{array}{l}\text { Espaços que colaborem } \\
\text { com o ensino e a } \\
\text { aprendizagem }\end{array}$ & $\begin{array}{l}\text { O ambiente não deve constranger ou inibir a aprendizagem. Ele deve permitir } \\
\text { experiências e atividades diversas que incluam os diferentes tipos de } \\
\text { aprendizado. Além disso, ele deve aceitar as especificidades de cada } \\
\text { estudante. }\end{array}$ \\
\hline Espaços envolventes & $\begin{array}{l}\text { Os espaços do ambiente escolar devem ser entendidos como pertencentes a } \\
\text { seus usuários e à comunidade do entorno. O ambiente físico deve estabelecer } \\
\text { uma efetiva conexão com o contexto urbano local. }\end{array}$ \\
\hline
\end{tabular}

Fonte: adaptado de Building Futures (2004).

Quadro 2 - Parâmetros de projeto da arquitetura escolar segundo Nair, Fielding e Lackney (2013)

\begin{tabular}{|c|c|}
\hline Parâmetro & Descrição \\
\hline $\begin{array}{l}\text { Salas de aula, ambientes de } \\
\text { ensino e aprendizado }\end{array}$ & $\begin{array}{l}\text { Novas metodologias de ensino - diversas modalidades e } \\
\text { necessidades espaciais }\end{array}$ \\
\hline Entrada convidativa & Identidade; acolhimento; significado na comunidade \\
\hline Espaços de exposição & Valorização do aprendizado; elementos decorativos \\
\hline $\begin{array}{l}\text { Espaço individual para } \\
\text { armazenar materiais }\end{array}$ & Local para armazenar materiais pessoais - perto da área de estudo \\
\hline Laboratórios de ciências e artes & Trabalhos manuais; aprendizado ativo; infraestrutura necessária \\
\hline Arte, música e atuação & $\begin{array}{l}\text { Espaços de exposição, apresentação, áreas de preparação dessas } \\
\text { atividades }\end{array}$ \\
\hline Áreas de educação física & Atividades externas e internas; diversificação da prática física \\
\hline Áreas de alimentação & Espaços casuais; diversidade; valorização da alimentação saudável \\
\hline Transparência & Educação e aprendizagem são visíveis e celebradas na escola \\
\hline Vistas interiores e exteriores & Descanso da visão; interação \\
\hline Tecnologia distribuída & Presente em todo o ambiente escolar \\
\hline $\begin{array}{l}\text { Conexão entre espaços externos } \\
\text { e internos }\end{array}$ & $\begin{array}{l}\text { Valorização da área externa e sua relação com as atividades do } \\
\text { interior do edifício }\end{array}$ \\
\hline Mobiliário & Confortável; adequado à ergonomia \\
\hline Espaços flexíveis & Expansão; diversidade de usos; generosidade \\
\hline Campfire & $\begin{array}{l}\text { Modalidade de ensino focada na figura central de um professor ou } \\
\text { especialista }\end{array}$ \\
\hline Wateringhole & Modalidade de ensino focada no ensino entre os próprios alunos \\
\hline Cavespace & Modalidade de ensino focada no indivíduo; introspecção, reflexão \\
\hline $\begin{array}{l}\text { Projeto para inteligências } \\
\text { múltiplas }\end{array}$ & Explorar os diversos tipos de habilidades e conhecimentos \\
\hline Iluminação natural & $\begin{array}{l}\text { Papel fundamental na qualidade do espaço para visualização das } \\
\text { atividades }\end{array}$ \\
\hline Ventilação natural & Conforto térmico; ventilação cruzada \\
\hline Iluminação, cor e aprendizagem & $\begin{array}{l}\text { Pensadas de acordo com a atividade do local; possibilidade de } \\
\text { manipulação do tipo e quantidade de luz nos espaços }\end{array}$ \\
\hline Elementos de Sustentabilidade & Projeto de alto padrão de desempenho \\
\hline Assinatura local & Comunidade; pertencimento; acolhimento; valores da comunidade \\
\hline Conexão com a comunidade & Valores e relações com a comunidade do entorno \\
\hline Síntese dos parâmetros & Todos os parâmetros juntos \\
\hline
\end{tabular}

Fonte: adaptado de Nair, Fielding e Lackney (2013). 
Quadro 3 - Parâmetros de projeto da arquitetura escolar segundo ISSA

\begin{tabular}{|c|c|c|}
\hline Agrupamento & Parâmetro & Descrição \\
\hline \multirow{6}{*}{ Sala de aula } & Flexibilidade & $\begin{array}{l}\text { Permite diferentes formações para diferentes } \\
\text { metodologias pedagógicas }\end{array}$ \\
\hline & Adaptabilidade & $\begin{array}{l}\text { Diversas atividades podem ser desenvolvidas no mesmo } \\
\text { espaço }\end{array}$ \\
\hline & Ensino em grupo & $\begin{array}{l}\text { Favorecimento do processo de inclusão social e } \\
\text { educacional }\end{array}$ \\
\hline & Relação professor-aluno & $\begin{array}{l}\text { Melhorar a interação entre os dois usuários na sala de } \\
\text { aula }\end{array}$ \\
\hline & Vistas externas & Estímulo ao aprendizado através do descanso do olhar \\
\hline & Salas duplas & $\begin{array}{l}\text { Possibilidade de criar interação entre as duas salas e um } \\
\text { espaço que permita atividades que exijam mais espaço }\end{array}$ \\
\hline \multirow{18}{*}{ Edifício } & Identidade local & Significado na comunidade \\
\hline & Entrada convidativa & $\begin{array}{l}\text { Proporciona segurança e receptividade tanto para alunos } \\
\text { como para pais e funcionários }\end{array}$ \\
\hline & Espaços de exposição & $\begin{array}{l}\text { Valorização do desenvolvimento de cada criança e } \\
\text { adolescente }\end{array}$ \\
\hline & Espaço de armazenamento & Criação de um vínculo do aluno com a escola \\
\hline & Período integral & Incentivo ao ensino integral \\
\hline & Apresentações espontâneas & Incentivo à prática de artes performáticas \\
\hline & $\begin{array}{l}\text { Apresentações } \\
\text { programadas }\end{array}$ & Incentivo à prática de artes performáticas \\
\hline & Biblioteca convidativa & $\begin{array}{l}\text { Incentivo ao uso de recursos de consulta, como livros, } \\
\text { revistas, etc. }\end{array}$ \\
\hline & Horta & $\begin{array}{l}\text { Proporcionar a participação dos alunos no preparo do } \\
\text { alimento, no serviço aos colegas e incentivo a hábitos de } \\
\text { alimentação saudável }\end{array}$ \\
\hline & Composteira & $\begin{array}{l}\text { Consciência para o desenvolvimento sustentável, } \\
\text { possibilidade de o aluno levar esse aprendizado para sua } \\
\text { casa e para a comunidade }\end{array}$ \\
\hline & Telhado verde & $\begin{array}{l}\text { Consciência para o desenvolvimento sustentável, } \\
\text { possibilidade de o aluno levar esse aprendizado para sua } \\
\text { casa e para a comunidade }\end{array}$ \\
\hline & Atividade física & Incentivo às práticas esportivas \\
\hline & Luz e ventilação natural & Aproveitamento energético do edifício \\
\hline & Pisos & Melhor compreensão do aluno sobre espaço e sua função \\
\hline & Refeitórios & Humanização do refeitório \\
\hline & Alimentação saudável & $\begin{array}{l}\text { Ensino prático a respeito de saúde, alimentação e bem- } \\
\text { estar }\end{array}$ \\
\hline & Acessibilidade & $\begin{array}{l}\text { Todos os ambientes devem ser acessíveis a pessoas com } \\
\text { necessidades especiais }\end{array}$ \\
\hline & Tratamento do lixo & $\begin{array}{l}\text { Compreensão dos alunos a respeito da produção de } \\
\text { resíduos sólidos }\end{array}$ \\
\hline
\end{tabular}

Fonte: adaptado de Issa (2017).

A literatura indica diversas vantagens para a aplicação desse tipo de ferramenta (BRANDT, 2006; BJÖGVINSSON; EHN; HILLGREN, 2012). Os jogos podem contribuir para o projeto, especialmente quando apoiados por outros materiais durante o processo de projeto; esses métodos rompem com hábitos e preconceitos, o que é essencial na atividade projetiva (HOLLAND; ROUDAVSKI, 2016). São baseados em elementos engajadores e exploram as características essenciais do "jogar", que incluem competição e objetivos, atividades desafiadoras, escolhas e elementos de fantasia (MOLONEY et al., 2017).

Os jogos podem propor sistemas capazes de organizar a participação dos envolvidos, com a principal vantagem de permitir a criação de um cenário comum, em que todos podem se relacionar (BRANDT, 2006). 
Funcionam também como facilitadores da comunicação e discussão, característica indispensável ao trabalho do arquiteto (BRKOVIC; CHILES, 2016).

As regras tornam-se forças diretivas dos diálogos, sem restringir a criatividade dos participantes (BRANDT; MESSETER, 2004). Isso possibilita o aprofundamento dos aspectos mais relevantes dos projetos, considerando os diversos tipos de usuários envolvidos. Aumenta-se a compreensão do processo de planejamento e de sua complexidade, e, consequentemente, o compromisso dos envolvidos. Também se obtém mais facilmente o consenso quanto a arranjos básicos do que com métodos tradicionais de busca de soluções (PEÑA; PARSHALL, 2012).

Além disso, as dinâmicas exploratórias de projeto podem engajar e divertir as pessoas, estimulando-as a participar desse tipo de atividade e criando uma atmosfera informal bastante produtiva no campo da criatividade.

De forma resumida, pode-se afirmar que jogos e dinâmicas podem facilitar os diálogos de projeto para o aprendizado mútuo de todos os envolvidos nas atividades. Eles funcionam muito bem no mapeamento de informações do contexto, assim como convidam a descobrir e criar novas representações compartilhadas de projeto (BRANDT; MESSETER, 2008).

\section{Método}

A metodologia utilizada para esta pesquisa trabalhou com abordagem qualitativa, fundamentada em revisão bibliográfica, acerca dos temas processo de projeto, arquitetura escolar e jogos. A literatura indicou o uso de um jogo como ferramenta de apoio ao desenvolvimento da etapa do plano de massas. Optou-se por trabalhar com um jogo de tabuleiro, apoiado por baralho de cartas-conceito. A busca pelos conceitos definidores das cartas do jogo concentrou-se na fase pretendida para o jogo, a saber, o plano de massas, o que significou um recorte de uma literatura que é bastante vasta para a arquitetura escolar.

Uma primeira versão foi elaborada como apoio à fase inicial de criação. Tal ferramenta se baseia nos parâmetros de projeto indicados pela literatura como essenciais a um projeto arquitetônico de qualidade. Essa primeira versão foi submetida para avaliação de dois tipos de profissionais, a saber, pedagogos e arquitetos atuantes com a tipologia escolar, através de entrevistas estruturadas por questionários. Dois questionários foram elaborados, um para cada tipo de profissional a ser entrevistado.

O questionário voltado para a aplicação com os pedagogos abordava quatro temáticas:

(a) a contextualização (informações gerais sobre a atuação do pedagogo e sua relação com os ambientes escolares);

(b) a sala de aula (proposto desenho de uma sala de aula ideal); e

(c) o edifício escolar; e os conceitos propostos para o jogo.

Já o questionário voltado para a aplicação com os arquitetos pretendeu coletar dados a respeito do funcionamento da dinâmica projetual de cada escritório, ou seja, compreender na prática como se dá o processo de projeto dos escritórios de arquitetura ligados ao projeto de escolas e também conhecer quais os parâmetros considerados essenciais para a tipologia escolar. O questionário proposto possui três partes. A primeira parte, denominada contextualização, pretendia obter informações gerais a respeito do escritório, de seu funcionamento e de sua experiência com o projeto de escolas. A segunda etapa, chamada de plano de massas, buscava compreender melhor a definição que o escritório dava a essa etapa do processo de projeto. $\mathrm{Na}$ última etapa, as cartas da primeira versão do jogo eram apresentadas ao arquiteto entrevistado, para serem avaliadas segundo sua experiência de projeto.

Essas entrevistas pretenderam a verificação e validação dos parâmetros levantados pela revisão bibliográfica: se os pedagogos os identificavam como essenciais à prática pedagógica da rotina escolar e se os arquitetos concordavam que eram esses os conceitos essenciais a uma arquitetura de alto padrão de desempenho na tipologia escolar. Foram selecionados 5 arquitetos e 5 pedagogos para participarem dessa etapa da pesquisa: os arquitetos com projetos premiados na área escolar ou com ampla experiência comprovada na área, e pedagogos experientes e com atuação na esfera pública ou privada.

A partir dessas entrevistas, uma segunda versão do jogo foi proposta, para início dos experimentos práticos. Esses experimentos foram realizados utilizando-se a metodologia dos grupos focais, verificando ocorrências na qualidade da interação entre os participantes e nos aparentes benefícios no processo criativo. Foram testadas tanto as cartas-conceito (verificando questões de formato, de conteúdo e da imagem representativa)

94 Deliberador, M. S.; Taralli, C. H.; Peres, G. 
quanto o tabuleiro desenvolvido. Para cada aplicação, tanto as cartas-conceito como o tabuleiro foram revistos, sempre buscando o aprimoramento da ferramenta.

A amostra desses experimentos foi definida em dois grupos:

(a) grupos focais realizados em ambiente universitário - essa amostra consistiu em duas aplicações, uma em universidade pública e outra em universidade particular, ambas com as turmas do terceiro ano e em disciplinas de projeto cuja temática era a arquitetura escolar. A turma da primeira aplicação tinha vinte e cinco alunos, que formaram cinco grupos focais, de cinco elementos cada (uma dupla e um trio das equipes de projeto). Na segunda aplicação, a turma tinha vinte e três alunos, que formaram três grupos focais de seis elementos cada e um grupo focal de cinco elementos (três duplas ou dois trios de equipes de projeto); e

(b) grupos focais realizados com grupos de profissionais do mercado com interesse e/ou experiência em projetos escolares, recrutados por meio de chamada para curso livre na área da arquitetura escolar -essa amostra consistiu em duas aplicações. Para a primeira aplicação, formou-se um grupo focal de cinco elementos, sendo na primeira uma equipe de três profissionais e uma de dois profissionais, e na segunda aplicação, duas equipes de dois profissionais cada.

Após a aplicação, questionários foram entregues aos participantes para que estes avaliassem a dinâmica proposta. Todos os participantes deveriam responder individualmente aos questionários, nos dois tipos de grupos realizados. A partir das respostas, e também da observação das pesquisadoras, após a fase de aplicações, desenvolveu-se a versão final do jogo, com alguns ajustes em relação às últimas testadas.

Por se tratar de atividade com interação com os membros envolvidos nos grupos focais, a pesquisa foi submetida ao Comitê de Ética na Plataforma Brasil, tendo sido aprovada sem restrições.

\section{Resultados e discussões}

O próprio desenvolvimento da ferramenta se constituiu em um dos resultados, uma vez que esse era um dos objetivos da pesquisa e que o levantamento bibliográfico realizado demonstrou a importância desse tipo de instrumento no processo de projeto. Nesse sentido, a seção inicial dos resultados foi feita com a descrição resumida do processo de criação da ferramenta, a qual se iniciou com o levantamento dos diversos tipos de instrumento que poderiam apoiar a etapa inicial do processo criativo. Optou-se pela criação de um jogo, dadas as vantagens apresentadas na literatura para esse formato.

\section{Desenvolvimento do jogo}

A ferramenta desenvolvida se utiliza do formato de um jogo de tabuleiro para cumprir seus objetivos, apoiando-se na fundamentação teórica apresentada anteriormente. É constituído de um tabuleiro, um manual de instruções e 35 cartas-conceito, cada uma representando um parâmetro essencial a essa fase do processo. Sua dinâmica baseou-se no jogo Chutes andLadders.

As cartas-conceito foram elaboradas com referência nos conceitos obtidos na revisão da literatura sobre a tipologia escolar e transformados em parâmetros de projeto. Para isso, a elaboração de cada carta foi feita com o nome do parâmetro e uma ilustração esquemática sobre o conceito abordado, de acordo com a metodologia proposta por Alexander, Ishikawa e Silverstein (2013).

A elaboração do jogo tem algumas versões, todas testadas, que trouxeram importantes contribuições para a elaboração da versão final. Muitos foram os desafios encontrados no desenvolvimento dessa ferramenta. Os conceitos dessa etapa devem ser focados nas questões cruciais da transição do programa para a etapa de criação. Desse modo, necessitam ser amplos (no sentido de não estarem focados em definições e refinamentos dos detalhes do edifício) e devem abarcar todas as definições do partido arquitetônico.

A partir da primeira seleção de parâmetros, foram elaborados dois questionários para serem utilizados como apoio das entrevistas estruturadas, a serem realizadas com arquitetos e pedagogos.

Em termos gerais, as entrevistas foram muito positivas, considerando os resultados que elas trouxeram e as contribuições no desenvolvimento da ferramenta. Os entrevistados se sentiram bastante estimulados para debater sobre o assunto e conseguiram contribuir com sua percepção a respeito da temática abordada. $\mathrm{O}$ questionário permitiu criar uma linguagem comum entre a arquitetura e a pedagogia no sentido de permitir um diálogo produtivo.

As entrevistas com os pedagogos permitiram adquirir maior sensibilização a respeito da relação entre a prática diária da educação e suas necessidades espaciais, demonstrando, ainda mais, a importância de 
reflexões dos arquitetos nesse sentido, que podem ser facilitadas pela ferramenta do jogo desenvolvido nessa pesquisa. Já as entrevistas com arquitetos possibilitaram a confirmação dos conceitos selecionados, assim como a inclusão de outros, relacionados à prática arquitetônica.

Outro desafio enfrentado na criação do jogo foi a seleção das imagens que deveriam ilustrar as cartasconceito: ao mesmo tempo em que deveriam ser genéricas, para não induzir soluções projetuais, deveriam ser instigantes e provocativas, gerando discussões sobre os conceitos que elas abarcam e sobre como esses devem se desdobrar no projeto arquitetônico, desde suas fases iniciais. Na primeira versão, as cartasconceito eram frente e verso e apresentavam imagens retiradas da literatura. No entanto, as aplicações demonstraram que o verso quase não era observado pelos participantes e que o conjunto do jogo necessitava de uma linguagem mais uniforme com relação às imagens. Também se sentiu necessidade da numeração dos conceitos e da divisão em temas. Nesse sentido, já a segunda versão passou a ter apenas uma face para cada carta-conceito, e optou-se por imagens elaboradas como croquis, à mão livre, escaneadas, vetorizadas e complementadas por textos em programa de edição de imagem, de forma a se obter um conjunto com uma linguagem visual uniforme e adequado à fase que se destina. As cartas foram numeradas e divididas em grupos, cada um com uma cor.Para a versão final, ajustes nas imagens ainda foram feitos, incorporando sugestões dos participantes e novos agrupamentos propostos conforme o Quadro 4.As Figuras 2 e 3 apresentam dois exemplos da evolução das cartas-conceito, nas versões propostas pelo jogo.

O último desafio enfrentado relacionou-se à jogabilidade da ferramenta. De acordo com McGonigal (2012), um bom jogo deve apresentar quatro características essenciais: regras e objetivos bem definidos e adequados, um sistema de feedback e a participação voluntária dos envolvidos. Nesse sentido, a própria dinâmica do Chutes andLadders proposta já teve uma contribuição inicial. Mas, além disso, outras estratégias foram incorporadas às regras e, principalmente, ao tabuleiro do jogo, para conferir maior competitividade, como incluir sistemas de pontuação para discussões de cada conceito. A evolução dos tabuleiros (Figura 4) demonstra que, inicialmente, ele era composto apenas das casas com os números das cartas-conceito. Com a experiência dos testes, incorporaram-se outras características de jogos, para conferir uma dinâmica mais intensa e, consequentemente, motivar a participação dos envolvidos.

Quadro 4 - Lista de cartas-conceito - versão final do jogo

\begin{tabular}{|c|c|}
\hline Grupo & Parâmetro \\
\hline \multirow{6}{*}{ Conceitos subjetivos } & Humanização \\
\hline & Espaços inspiradores \\
\hline & Assinatura local \\
\hline & Senso de pertencimento \\
\hline & Conexão com a comunidade \\
\hline & Inteligências múltiplas \\
\hline \multirow{6}{*}{ Conceitos de desempenho } & Acesso \\
\hline & Conforto térmico \\
\hline & Conforto acústico \\
\hline & Conforto luminoso \\
\hline & Acessibilidade \\
\hline & Segurança \\
\hline \multirow{3}{*}{ Conceitos espaciais } & Conexão entre espaços internos e externos \\
\hline & Transparência \\
\hline & Espaços flexíveis, variáveis e adaptáveis \\
\hline \multirow{7}{*}{ Partes de um todo } & Espaços que colaborem com o ensino \\
\hline & Espaços para ensino ambiental \\
\hline & Espaços para artes performáticas \\
\hline & Espaços para exposição \\
\hline & Espaços para atividade física \\
\hline & Espaços para os profissionais \\
\hline & Espaços livres \\
\hline \multirow{6}{*}{ Conceitos de ensino } & Aprendizado por tutoria \\
\hline & Aprendizado individual \\
\hline & Aprendizado em grupos grandes \\
\hline & Aprendizado informal \\
\hline & Aprendizado tradicional \\
\hline & Síntese dos parâmetros \\
\hline
\end{tabular}

96 Deliberador, M. S.; Taralli, C. H.; Peres, G. 
Figura 2 - Evolução das cartas-conceito a partir das aplicações - exemplo da carta-conceito espaço para os profissionais

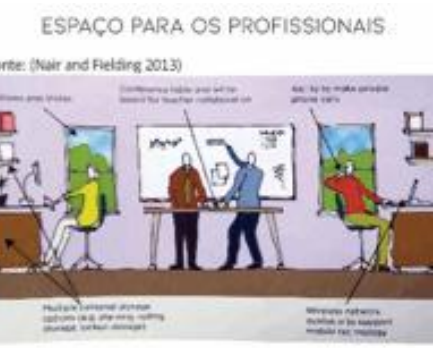

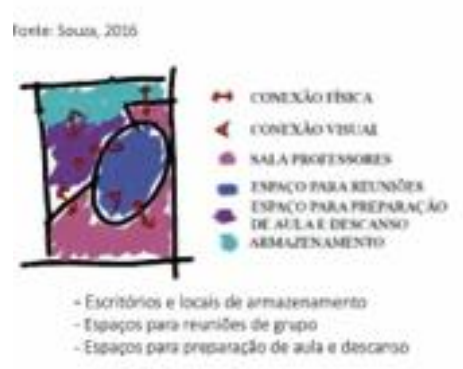

Versão preliminar

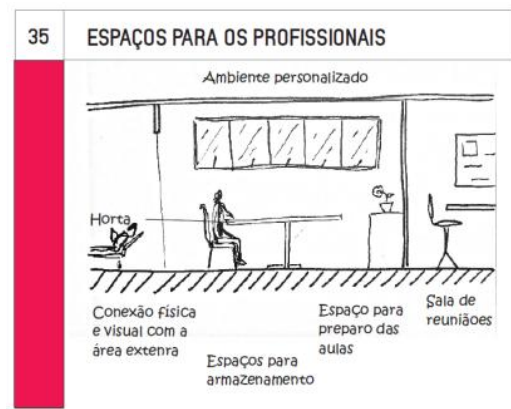

Versão intermediária

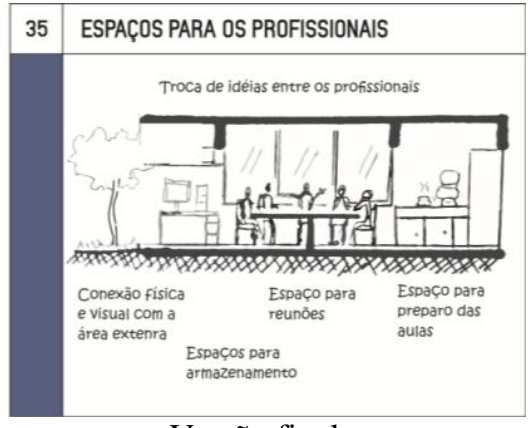

Versão final

Figura 3 - Evolução das cartas-conceito a partir das aplicações - exemplo da carta-conceito aprendizado informal

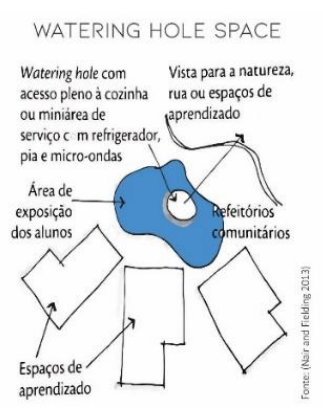

Versão preliminar

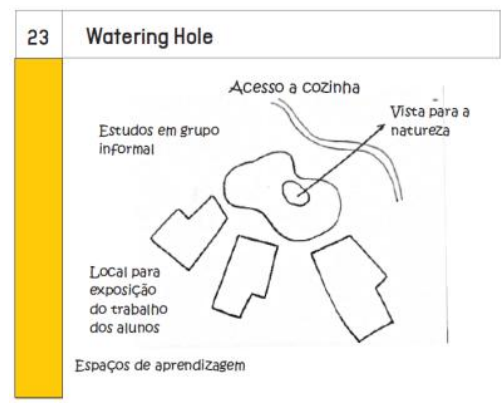

Versão intermediária

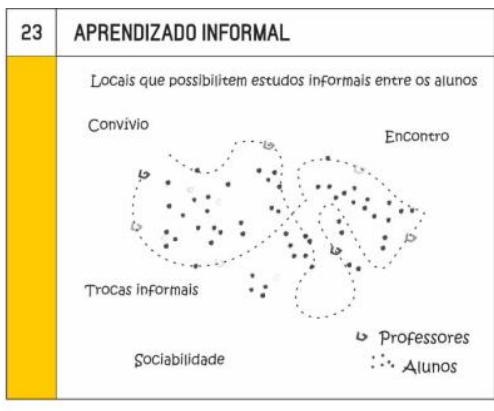

Versão final

Figura 4 - Evolução dos tabuleiros a partir das aplicações

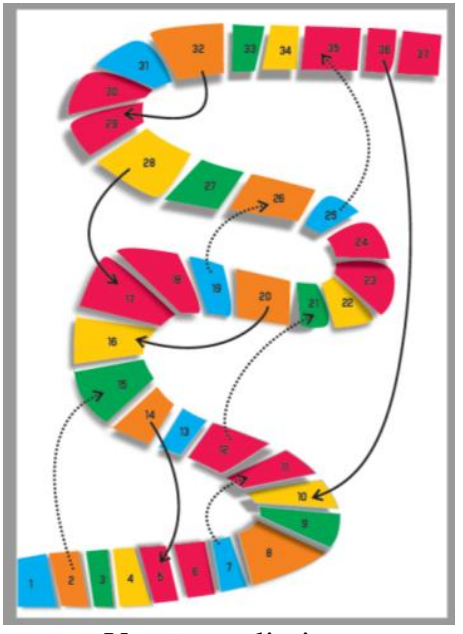

Versão preliminar

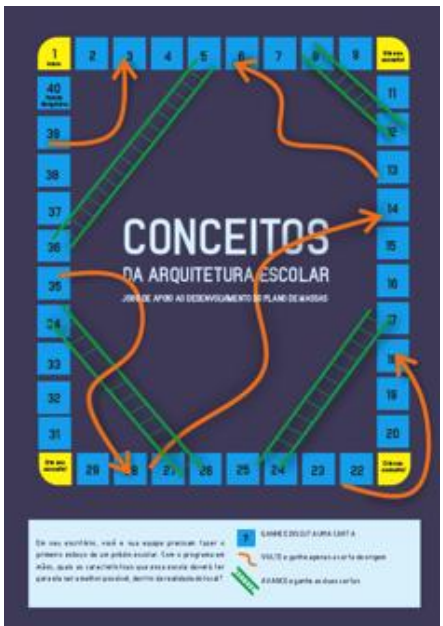

Versão intermediária

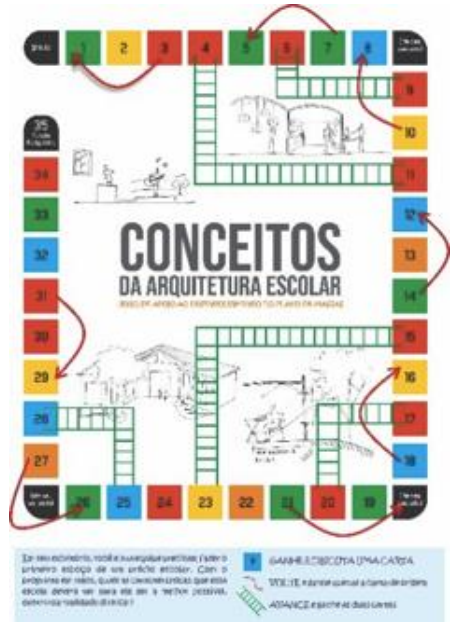

Versão final 
A versão final do jogo ficou definida com 35 conceitos, divididos em grupos a saber (conforme Quadro 4):

(a) conceitos subjetivos;

(b) conceitos de desempenho;

(c) conceitos espaciais;

(d) partes de um todo; e

(e) conceitos de ensino.

Com relação a sua aplicação, a dinâmica da ferramenta é dividida em três etapas. Na primeira etapa, cada jogador movimenta-se no tabuleiro de acordo com o lançamento dos dados. Se a casa sorteada possuir escadas verdes, significa que o jogador ganhou um atalho e deve avançar para a casa indicada, ganhando as duas cartas-conceito (a da casa de origem do tabuleiro e a da casa de destino). No entanto, se a casa onde o pino cair possuir setas vermelhas, o jogador foi punido e deve recuar para a casa indicada, ganhando apenas o conceito da carta de origem. Em cada casa em que o jogador para, ele recebe uma carta-conceito, e esta deve ser guardada para ser usada na etapa seguinte. Ao receber o conceito, a carta deve ser lida e mostrada para todos os participantes, e a equipe que a recebeu deve promover uma discussão (duração de 2 min). Essa discussão deve ser validada pelas equipes oponentes para que a equipe da vez ganhe um ponto.

Ao longo do tabuleiro existem casas "Crie seu conceito". As equipes que pararem nessa casa deverão elaborar um conceito que consideram essencial para o projeto em questão. A primeira equipe que chegarao fim do jogo receberá dez pontos. O vencedor do jogo é aquele que obtiver maior pontuação ao final da primeira etapa.

Para a segunda etapa, os participantes recebem um terreno, um programa de uma escola e a proposta de que desenvolvam em $1 \mathrm{~h}$ um plano de massas que apresente as cartas-conceito obtidas na etapa anterior. E, por fim, a terceira e última etapa consiste na apresentação por cada equipe de como cada conceito foi incorporado ao plano de massas desenvolvido.

\section{Aplicações do jogo: ambiente universitário $x$ ambiente profissional}

As aplicações foram essenciais para o desenvolvimento das versões, principalmente com relação às imagens das cartas-conceito e a definição do tabuleiro.

Dois tipos de aplicação foram feitos. As aplicações no ambiente de ensino ocorreram da seguinte forma: organizaram-se as equipes de projeto (formadas de dois ou três alunos), que já haviam previamente desenvolvido os programas arquitetônicos e visitado o terreno onde deveria ser implantado o projeto.

Para essas aplicações das universidades, a dinâmica foi proposta em duas etapas.Para a primeira etapa, do jogo de tabuleiro, as equipes de projeto eram oponentes entre si. A dinâmica funcionou muito bem, os alunos mostraram-se envolvidos e acharam a atividade motivadora e envolvente (Figuras 5 e 6 ). No entanto, ao migrarem para a segunda etapa, houve dificuldade de transpor os conceitos das cartas da primeira etapa para o desenvolvimento de um plano de massas.

\section{Figura 5 - Aplicações em ambientes universitários - aplicação 1}

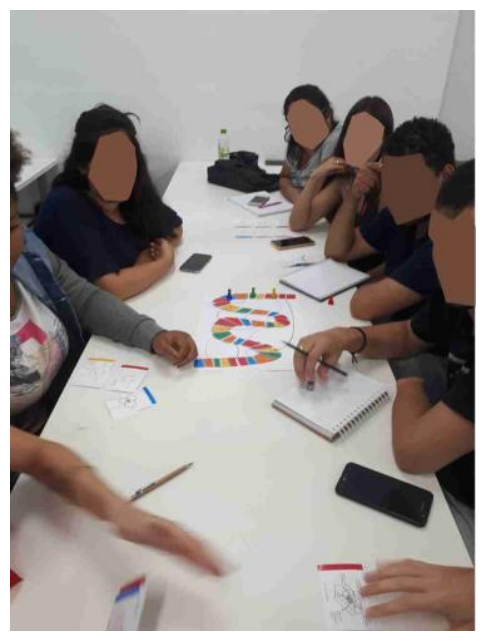

98 Deliberador, M. S.; Taralli, C. H.; Peres, G. 
Figura 6 - Aplicações em ambientes universitários - aplicação 2

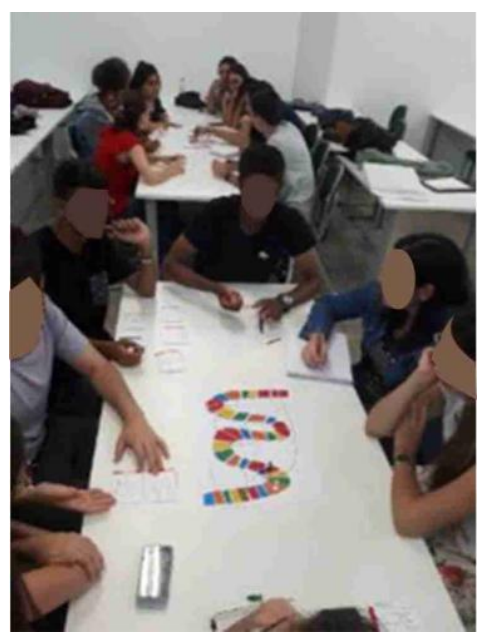

Para as aplicações junto aos profissionais foram realizados dois grupos focais, ambos formados por arquitetos interessados na tipologia escolar (Figuras 7 e 8). A primeira etapa do jogo se deu com cada equipe representando um pino. O jogo foi aplicado, e cada equipe recebeu um número de cartas-conceito para utilizar na etapa seguinte. Na segunda parte do jogo, os jogadores deveriam produzir um plano de massas, a partir das cartas-conceito recebidas na etapa anterior, de um programa básico com as áreas que cada ambiente deveria ter e da planta de um terreno onde deveria ser feita a implantação do projeto.

Observou-se ampla discussão dos conceitos e de como estes poderiam ser aplicados na implantação do projeto, desde a primeira etapa do jogo, além do amplo engajamento dos profissionais e de uma rica troca de experiências e compartilhamento do repertório de cada membro da equipe, demonstrando o caráter colaborativo que esse tipo de atividade pode ter.

Para o primeiro grupo focal, em uma das equipes, os participantes rapidamente organizaram o programa proposto em dois fluxogramas de preparação ao projeto, anterior ao plano de massas propriamente dito (Figuras 9 e 10). Essa preparação colaborou intensamente para o entendimento do programa, tendo contribuído significativamente para a qualidade do plano de massas posteriormente elaborado, assim como para a eficiência na elaboração dele, realizada em menos de $1 \mathrm{~h}$ (Figura 11).

De modo geral, os planos de massas apresentaram de forma bastante clara os conceitos trazidos da primeira etapa do jogo, como pode ser observado nos exemplos das Figuras 11 e 12.

A dinâmica possibilitou uma atmosfera descontraída e favorável às manifestações criativas, tanto na aplicação em ambiente universitário como no profissional. A etapa do jogo de tabuleiro foi rica e engajadora, criando um ambiente colaborativo, mesmo dentro da competição proposta. Já a etapa de elaboração do plano de massas mostrou-se mais introspectiva e de reflexão dentro das equipes, trazendo resultados promissores, como esboços de um projeto escolar.

\section{Considerações e avaliação sobre as aplicações do jogo}

A observação realizada durante as aplicações confirmou aspectos apresentados como vantagens da utilização de jogos que haviam sido levantados na literatura: foi criado um ambiente leve de discussão, mas focado nos parâmetros considerados essenciais a uma arquitetura escolar de qualidade. Os assuntos eram aprofundados e em poucos momentos se perdia o foco da reflexão.

Os questionários aplicados junto aos participantes indicaram avaliação bastante positiva do uso da ferramenta. As questões discorriam sobre uma avaliação geral da ferramenta, uma análise da aplicabilidade dos conceitos para a etapa do plano de massas, a avaliação se jogos como esse facilitam o aprendizado e se podem ou não ser utilizados no meio profissional. No ambiente universitário, todos os alunos responderam aos questionários, e no ambiente profissional, 8 dos 9 participantes responderam. 
Figura 7 - Aplicações em ambientes profissionais - aplicação 1

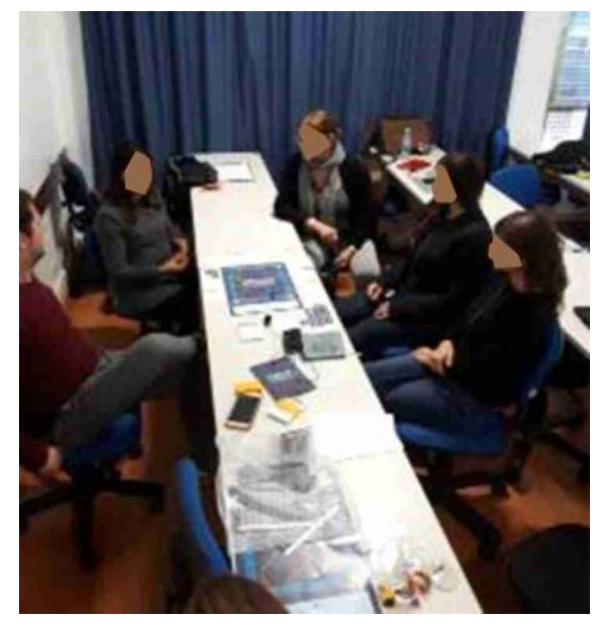

Figura 8 - Aplicações em ambientes profissionais- aplicação 2

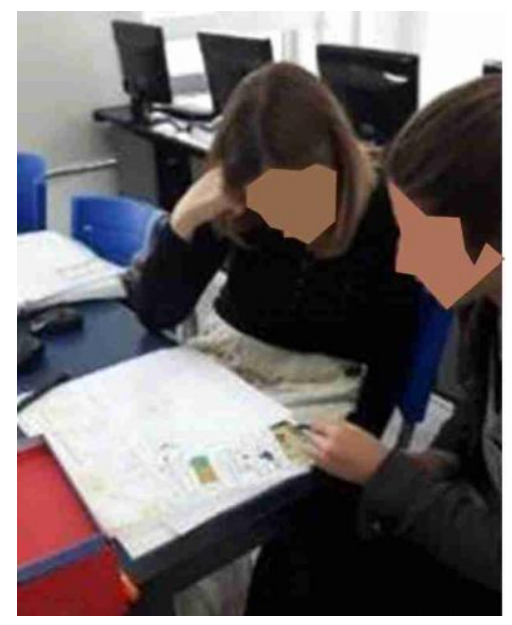

Figura 9 - Organização de áreas e fluxos para o edifício escolar

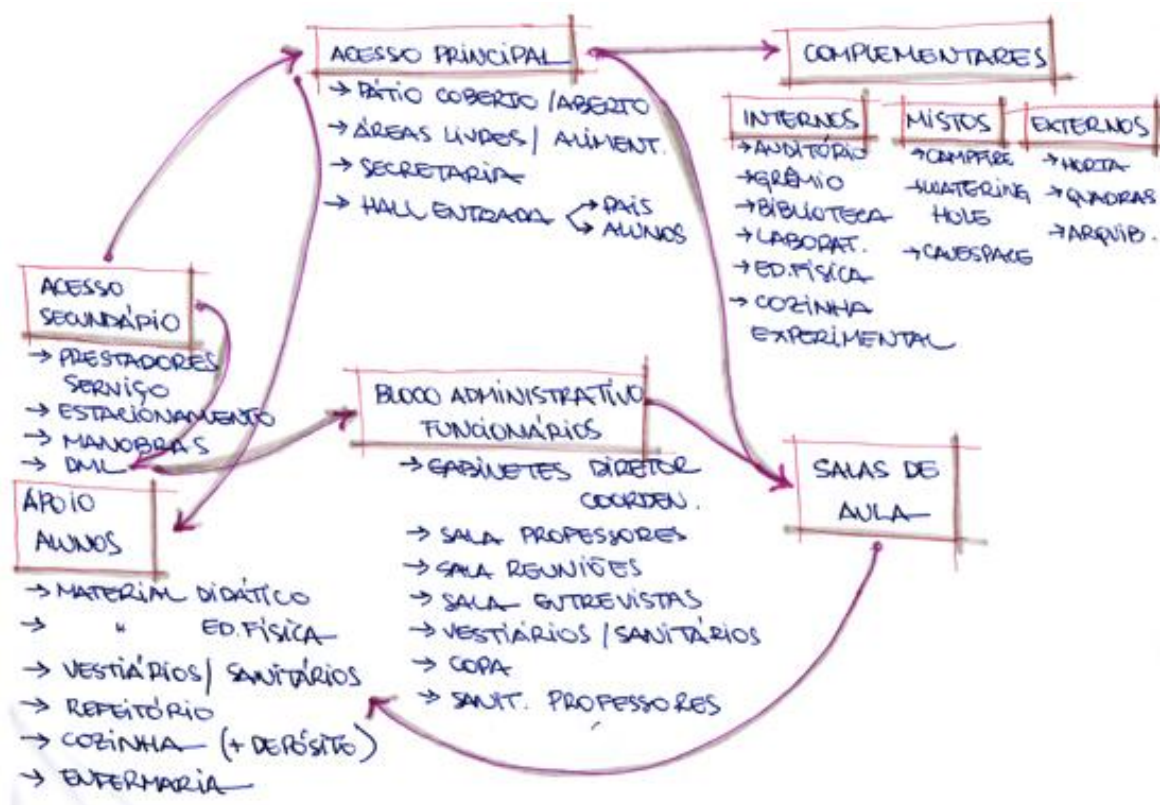

100 Deliberador, M. S.; Taralli, C. H.; Peres, G. 
Figura 10 - Fluxograma para preparação do plano de massas
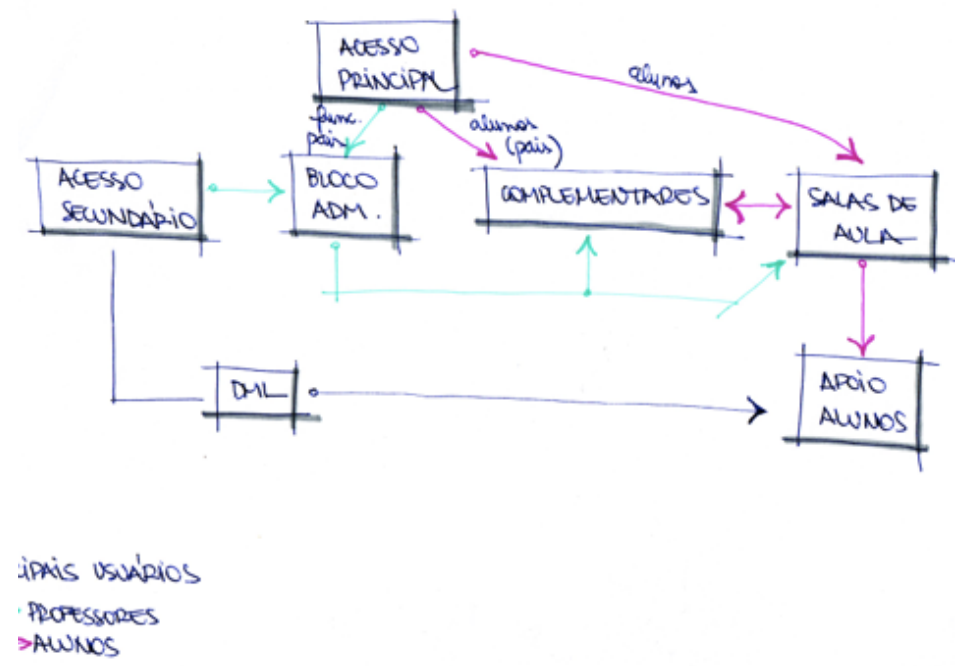

Figura 11 - Exemplo de plano de massasobtido na segundaetapa do jogo - parâmetros: espaçosverdes, asrelaçõesespaçosinternos e externos e vistas, e osespaços de ensino e aprendizagem

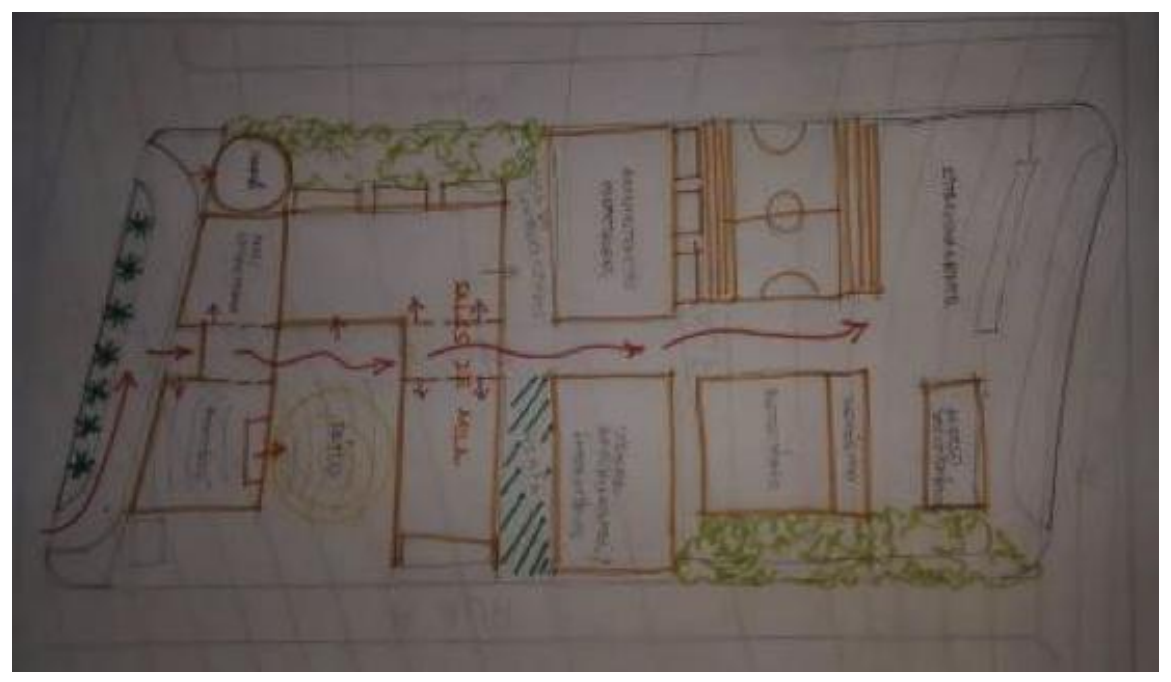

Figura 12 - Exemplo de plano de massasobtido na segundaetapa do jogo - parâmetros: espaçosverdes, espaçosparaatividadefísica, conexãoespaçosinternos e externos, e espaçosparalaboratórios

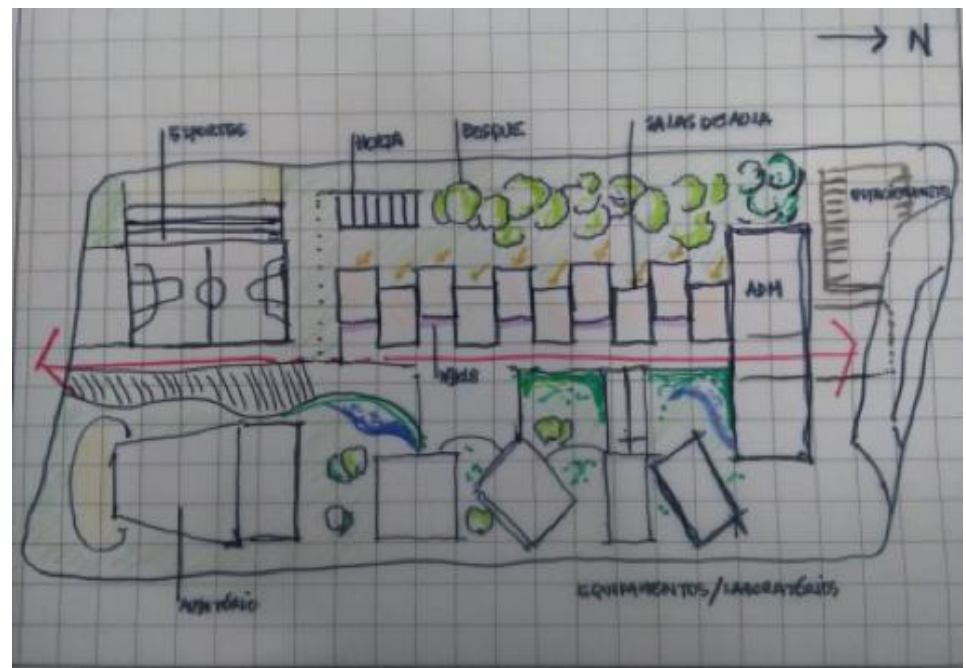


Alguns resultados merecem aqui ser destacados. A avaliação geral do jogo sempre foi muito favorável, tanto para alunos como para profissionais (Figuras 13 e 14).

A incorporação de conceitos trazidos pela ferramenta para o projeto também é amplamente bem avaliada (Figura 15 e 16). Ao serem questionados se ferramentas como essa (jogos) podem facilitar o aprendizado, $100 \%$ responderam que sim, tanto entre os alunos como entre os profissionais.

Com relação ao uso de tais ferramentas no meio profissional, a avaliação também é bem positiva. Os alunos vislumbram esse uso após formados, e a ampla maioria acredita que esse tipo de jogo possa ser incorporado à prática do mercado (Figura 17). Entre os profissionais esse número foi também bastante elevado (Figura 18). Por fim, ressalta-se que os jogos ainda foram pouco explorados como ferramentas de suporte ao processo de projeto: a maior parte dos entrevistados nunca havia utilizado esse tipo de dinâmica (Figuras 19 e 20).

Figura 13 - Avaliaçãogeral do jogonoambienteacadêmico (alunos)

\section{Avaliação Geral dos Jogos - Alunos}

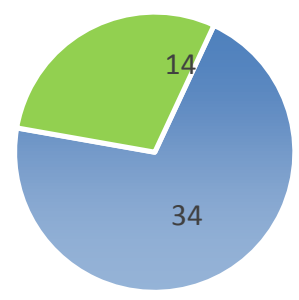

- Ótima/Boa

- Regular

Figura 14 - Avaliaçãogeral do jogonoambienteprofissional

Avaliação Geral do Jogo - Profissionais

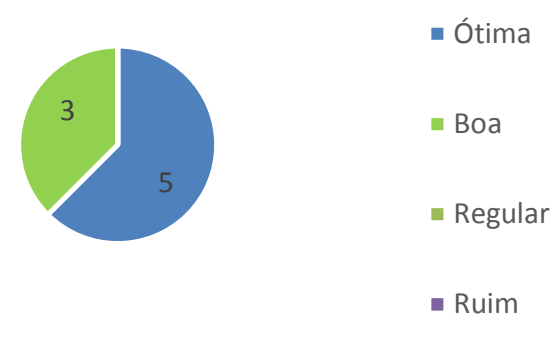

Figura 15 - Avaliaçãosobre a incorporação de conceitosaoprojetonoambienteacadêmico (alunos)

\section{Avaliação se a ferramenta possibilita incorporação de conceitos ao projeto - Alunos}

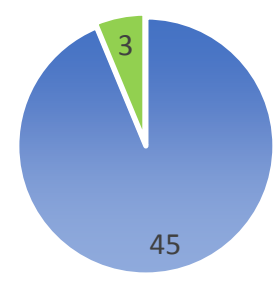

$$
\text { - Nim }
$$


Figura 16 - Avaliaçãosobre a incorporação de conceitosaoprojetonoambienteprofissional

\section{Avaliação se a ferramenta possibilita incorporação de} conceitos ao projeto - Profissionais

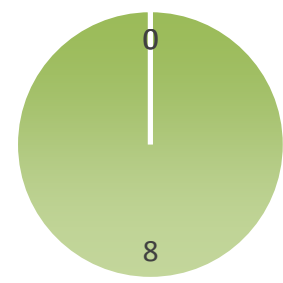

Figura 17 - Avaliaçãosobre o uso de jogosnomercadoprofissionalfeitanoambienteacadêmico (alunos)

Avaliação da ferramenta no Meio Profissional - Alunos

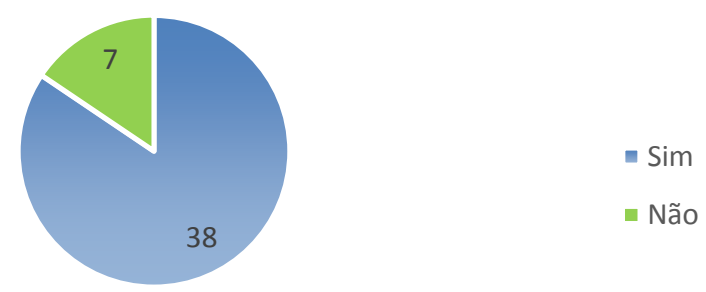

Figura 18 - Avaliaçãosobre o uso de jogosnomercadoprofissionalfeitapelosprofissionais

Avaliação da Ferramenta no meio profissional - Profissionais

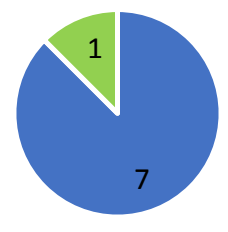

$\because \operatorname{Sim}$

— Não

Figura 19 - Utilizaçãoanterior de jogosnoambienteacadêmico (alunos)

\section{Utilização anterior de jogos \\ ou dinâmicas - alunos}

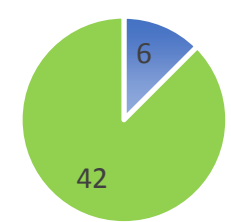

$$
\text { - } \text { - Sim }
$$


Figura 20 - Utilizaçãoanterior de jogosnoambienteprofissional

\author{
Uilização anterior de jogos ou dinâmicas - Profissionais
}

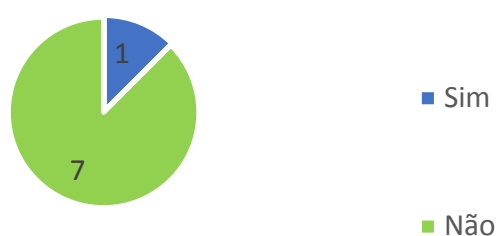

\title{
Conclusões
}

A importância de serem criadas novas ferramentas de apoio ao processo de projeto dos profissionais de arquitetura foi demonstrada pela literatura e ratificada nas entrevistas realizadas. Nesse sentido, desenvolver e estudar esse tipo de apoio é essencial para pesquisas nessa área e para sua aplicação na prática profissional, colaborando para um processo mais seguro e eficiente de tomada de decisões.

De modo resumido, pode-se apresentar como resultado desta pesquisa o desenvolvimento de uma ferramenta de apoio ao plano de massas, etapa inicial e essencial do processo criativo. Alguns pontos sobressaem e merecem destaque. $\mathrm{O}$ caráter colaborativo e de engajamento entre os participantes do jogo permitem a criação de um ambiente favorável às manifestações criativas e às discussões aprofundadas sobre os conceitos da tipologia escolar. Isso significa que, com o uso desse tipo de ferramenta, podem-se potencializar as ideias, fomentando discussões coletivas pertinentes ao projeto em desenvolvimento e favorecendo o engajamento dos envolvidos no processo de projeto na busca por melhores resultados. Essas discussões possibilitam que novas ideias, para além daquelas previstas na ferramenta, sejam trazidas à reflexão e, eventualmente, incorporadas ao projeto.

Outro aspecto a ser destacado como resultante deste estudo foi a ampliação e a aquisição de repertório por parte dos alunos em formação ou profissionais com menos experiência. Questões como conceitos, normas, aspectos subjetivos relacionados à criatividade e à cognição, entre outros, são fundamentais para a ideação e apareceram com clareza nas aplicações. Isso possibilitou a integração entre conceitos e conhecimentos em aquisição pelos alunos ou pelos profissionais menos experientes, que nem sempre são experimentados de forma interligada. Nessa visão, a ferramenta pode cumprir papel pedagógico no ensino e na formação de futuros profissionais, especialmente quando se intenciona prepará-los para atuar na contemporaneidade.

A aplicação para os dois grupos também indicou algumas melhorias necessárias. A etapa de elaboração do plano de massas funcionou muito bem para os profissionais. No entanto, a aplicação com os alunos sinalizou haver certa dificuldade de transpor os conceitos em esboços para a proposta de projeto. Os alunos pareciam não conseguir iniciar o projeto em si, numa clara dificuldade de transformar o programa arquitetônico em propostas de projeto, fruto da inexperiência inerente a essa fase da formação.

Nesse sentido, refletiu-se sobre como complementar a ferramenta para apoiá-los de forma mais efetiva. Indica-se que, para as próximas sessões com alunos, além do programa básico, ofereça-se um primeiro amadurecimento do programa, no formato de fluxogramas, como o elaborado pela equipe de profissionais e apresentados nas Figuras 9 e 10.

A seleção de conceitos propostos possibilitou uma rápida imersão dos profissionais e estudantes nas questões ligadas ao edifício escolar, estabelecendo um diálogo direcionado com as necessidades espaciais dos edifícios escolares atuais. Atender aos requisitos de um programa escolar não é suficiente para que o projeto esteja adequado. Os participantes das aplicações foram capazes de compreender isso de maneira muito simples e de rapidamente incorporar os conceitos do jogo em seus planos de massas.

Essa constatação merece destaque porque a transposição do programa em um plano de massas é sempre tarefa desafiadora. A ferramenta demonstrou apoiar essa etapa mesmo que os resultados dos desenhos ainda tenham permanecido restritos a estudos bidimensionais. Questões de volumetria e contexto, que também fazem parte do plano de massas, precisam ter sua discussão incentivada, o que sugere a necessidade de próximos passos para uma revisão eamadurecimento da ferramenta. 
De todo o modo, esta pesquisa destaca a necessidade de estudos sobre ferramentas de apoio ao processo de projeto, especialmente no formato de jogos, pelo potencial demonstrado como motivador de discussões certamente enriquecedoras do processo de projeto, que, consequentemente, podem oferecer promissores resultados, aferidos na qualidade dos edifícios escolares construídos no futuro.

\section{Referências}

ALEXANDER, C.; ISHIKAWA, S.; SILVERSTEIN, M. Uma linguagem de padrões. Porto Alegre: Bookman, 2013.

ALEXIOU, K. et al. Exploring the neurological basis of design cognition using brain imaging: some preliminary results. Design Studies, v. 30, n. 6, p. 623-647, 2009.

ALVES, F. Gamefication: como criar experiências de aprendizagem engajadoras: um guia completo. São Paulo: DVS, 2014.

AZEVEDO, G. A. N.; BASTOS, L. E. G.; BLOWER, H. S. Escolas de ontem, educação hoje: é possível atualizar usos em projetos padronizados? Cadernos PRQ, p. 59-66, 2007.

BAPTISTA, M. B. et al. E agora? Uma metodologia para discutir o desenho universal em projetos padronizados. In: ENCONTRO NACIONAL DE ERGONOMIA DO AMBIENTE CONSTRUÍDO, 4. Recife, 2016. Anais[...] Recife: ENEAC, 2016.

BARRETT, P. et al. A holistic, multi-level analysis identifying the impact of classroom design on pupils learning. Building and Environment, v. 59, p. 678-689, 2013.

BARRETT, P. et al. The impact of classroom design on pupils learning: final results of a holistic, multilevel analysis. Building and Environment, v. 89, p. 118-133, 2015.

BIANCHI, G. Métodos para estímulo à criatividade e sua aplicação em arquitetura. Campinas, 2008. Dissertação (Mestrado em Arquitetura e Urbanismo) - Faculdade de Engenharia Civil, Arquitetura e Urbanismo, Universidade Estadual de Campinas, Campinas, 2008.

BJÖGVINSSON, E.; EHN, P.; HILLGREN, P. A. Design things and design thinking: contemporary participatory design challenges. Design Issues, v. 28, n. 3, p. 101-116, jul. 2012.

BOYS, J. Towards creative learning spaces. London: Routledge, 2011.

BRANDT, E.; MESSETER, J. Facilitatingcollaborationthrough design games. In: CONFERENCE ON PARTICIPATORY DESIGN, 8., 2004. Proceedings [...] 2004.

BRANDT, E.; MESSETER, J.; BINDER, T. Formatting design dialogues: games and participation. CoDesign, v. 4, p. 51-64, 2008.

BRANDT, E.Designingexploratory design games: a framework for participation in participatory design. In: CONFERENCE ON PARTICIPATORY DESIGN, 9., 2006. Proceedings [...] 2006.

BRKOVIC, M.; CHILES, P. Spector: the sustainabilityinspector: participatoryteaching, learning and evaluation game for architects, architecturestudents and pupils. FactaUniversitatis, Series: Architecture and CivilEngineering, 2016. p. 1-20.

BUILDING FUTURES. 21st centuryschools: learningenvironments of the future. Building Futures, 2004.Rport.

CLARK, K. R.; QIAN, M. Game-base Learning an 21st centuryskills: a review of recentresearch. Computers in Human Behavior, v. 63, p. 50-58, 2016.

CROSS, N. Design cognition: results from protocol and otherempiricalstudies of design activity. In: DESIGN knowing and learning: cognition in design education. New York: Elsevier, 2001.

DELIBERADOR, M. S. Parâmetros da arquiteturaescolar e o jogo de cartascomo ferramenta de apoioaodesenvolvimento do programaarquitetônico. Campinas, 2016. Tese (DoutoradoemArquitetura, Tecnologia e Cidade) - Faculdade de EngenhariaCivil e Arquitetura, UniversidadeEstadual de Campinas, Campinas, 2016.

DESIGN, I. O. C.; FURNITURE, V. S.; DESIGN, B. M. The thirdteacher: 79 ways you can use design to transformteaching\&learning. New York: Abrams, 2010.

DUDEK, M. Schools and kindergartens: a design manual. London: Springer, 2007. 
FERNANDES, R. O. Desenvolvimento de programação arquitetônica de conforto ambiental: uma experiência acadêmica utilizando jogos de tabuleiro. Natal, 2017. Dissertação (Mestrado em Arquitetura) Centro de Tecnologia, Universidade Federal do Rio Grande do Norte, Natal, 2017.

FLORIO, W. Análise do processo de projeto sob a teoria cognitiva: sete dificuldades no atelier. Arquitetura Revista, v. 7, n. 2, p. 161-171, 2011.

HABRAKEN, N. J.; GROSS, M. D. Concept design games. Design Studies, v. 9, n. 3, p. 150-158, jul. 1987.

HERTZBERGER, H.Recentworks. Archis (Architecture, Urban Design, and Visual Arts), v. 12, 1986.

HILLE, T.Modernschools: a century of design for education. Hoboken: Wiley, 2011.

HOLLAND, A.; ROUDAVSKI, S. Design tools and complexity: mobile games and collectiveimagination. In: INTERNATIONAL CONFERENCE ON COMPUTER AIDED ARCHITECTURAL DESIGN IN EUROPE, 34., Finlândia, 2016. Proceedings [...] Oulu: eCAADe, 2016.

ISSA, D. H. Conceitos de projeto da arquitetura escolar e sustentabilidade.2017. Disponível em: https://www.blogdaliga.com.br/conceitos-arquitetura-escolar-sustentabilidade. Acessoem: 2 mar. 2019.

JOHANSSON, M. et al. Partner engaged design: new challenges for workplace design. In:

PARTICIPATORY DESIGN CONFERENCE, 2002, Malmö, 2002. Proceedings[...] Malmö, 2002.

KOWALTOWSKI, D. Arquitetura escolar: o projeto do ambiente de ensino. São Paulo: Oficina de Textos, 2011.

KOWALTOWSKI, D. C. C. K. et al. O processo de projeto em arquitetura: da teoria à tecnologia. São Paulo: Oficina de Textos, 2011.

KOWALTOWSKI, D. C. C. K. et al.Reflexão sobre metodologias de projeto arquitetônico.Ambiente Construído, Porto Alegre, v. 6, n. 2, p. 7-19, abr./jun. 2006.

LAWSON, B. Como arquitetos e designers pensam. São Paulo: Oficina de Textos, 2011.

LEITE, C. A. B. Linguagem e arquitetura: o problema do conceito. Revista de Teoria e História da Arquitetura e do Urbanismo, Belo Horizonte, v. 1, n. 1, p. 1-8, nov. 2000.

LLOYD, P.; LAWSON, B.; SCOTT, P. Can concurrentverbalizationreveal design cognition? Design Studies, v. 16, n. 2, p. 237-259, apr. 1995.

LLYOD, P. From design methods to future-focusedthinking: 50 years of design research. Design Studies, v. 48, p. 1-8, jan. 2017.

MARANGONI, R. F. A maquete manual com estímulo à criatividade na formação de arquitetos e urbanistas. Campinas, 2011. Tese (Doutorado em Arquitetura) - Faculdade de Engenharia Civil, Arquitetura e Urbanismo, Universidade Estadual de Campinas, Campinas, 2011.

MCGONIGAL, J. A realidade em jogo: porque os games nos tornam melhores e como eles podem mudar o mundo. Rio de Janeiro: Bestseller, 2012.

MOLONEY, J. et al. Serious games for integral sustainable design: level 1. In: INTERNATIONAL HIGHPERFORMANCE BUILT ENVIRONMENT CONFERENCE: A SUSTAINABLE BUILT

ENVIRONMENT CONFERENCE, Amsterdam, 2016. Proceedings[...] Amsterdam: Elsevier Science, 2017.

NAIR, P.; FIELDING, R.; LACKNEY, J.The language of school design: design patterns for 21st Century schools. Minneapolis: Designshare, 2013.

OBLINGER, D. Learning spaces. Washington: Educause, 2006. Disponível em: https://www.educause.edu/ir/library/pdf/PUB7102.pdf. Acessoem: 3 fev. 2019.

PEÑA, W. M.; PARSHALL, S. A. Problem seeking: an architectural programming primer. New York: John Wiley\& Sons, 2012.

PLOTKA, E. Better spaces for learning. London: Royal Institute of British Architects, 2016.

SANDERS, E. B. N.; BRANDT, E.; BINDER, T.A framework for organizing the tools and techniques of participatory design. In: BIENNIAL PARTICIPATORY DESIGN CONFERENCE, 11., 2010. Proceedings [...] 2010 .

106 Deliberador, M. S.; Taralli, C. H.; Peres, G. 
SANOFF, H. School design. New York: John Wiley \& Sons, 1994.

SANOFF, H. Schools designed with community participation. Washington: NCEF, 2001.

SARHAN, A.; RUTHERFORD, P. Embodied game agents in environmental design education. In: ECAADE - EDUCATION \& RESEARCH COMPUTER AIDED ARCHITECTURAL DESIGN EUROPE, 27. Bruxelas, 2009. Proceedings [...] Bruxelas, 2009.

SOUZA, L. N. de. Arquitetura escolar, parâmetros de projeto e modalidades de aprendizagem. Campinas, 2018. Dissertação (MestradoemArquitetura, Tecnologia e Cidade) - Faculdade de EngenhariaCivil e Arquitetura, UniversidadeEstadual de Campinas, Campinas, 2018.

UCCI, M. et al. Indoor schoolenvironments, physicalactivity, sitting, behaviour and pedagogy: a scopingreview. Building Research\& Information, v. 43, n. 5, p. 1-16, 2015.

WOOLNER, P. The design of learningspaces. New York: Continuum, 2010.

\section{Agradecimentos}

Os autores agradecem à Fapesp, pelo financiamento das pesquisas que fundamentaram o desenvolvimento desta pesquisa. Processos 2017/ 05699-3 e 2018/12647-2.

Marcella Savioli Deliberador

Departamento de Projeto, Faculdade de Arquitetura e Urbanismo | Universidade de São Paulo | Rua do Lago, 876 | São Paulo - SP - Brasil CEP 05508-080 | Tel.: (19) 99140-0230 | E-mail: marcelladeliberador@yahoo.com.br

Cibele Haddad Taralli

Departamento de Projeto, Faculdade de Arquitetura e Urbanismo | Universidade de São Paulo | Tel.: (11) 3091-4545 | E-mail: cibelet@usp.br

\section{Giovanna Peres}

Departamento de Projeto, Faculdade de Arquitetura e Urbanismo | Universidade de São Paulo | Tel.: (11)97199-7954 | E-mail: giovanna.peres@usp.br

\section{Ambiente Construído}

Revista da Associação Nacional de Tecnologia do Ambiente Construído Av. Osvaldo Aranha, $99-3^{\circ}$ andar, Centro

Porto Alegre - RS - Brasil CEP $90035-190$

Telefone: +55 (51) 3308-4084

Fax: +55 (51) 3308-4054

www.seer.ufrgs.br/ambienteconstruido

E-mail: ambienteconstruido@ufrgs.br 